\title{
LE PROFESSEUR JACQUes PELLEGRIN
}

\author{
par Paul VIVIER \\ Inspecteur des Eaux et Foréts: \\ Directeur de la Station Centrale d'Hydrobiologie appliquee.
}

C'est avec un profond sentiment de tristesse que ses nombreux amis ont accompagné à sa dernière demeure le Professeur J. Peli.kgrin, décédé après une très courte maladie le 12 aoât 1944. Les événements dramatiques d'alors qui avaient désorganisé le Service des lompes funèbres contribuèrent à donner à la cérémonie, en l'église Saint-Médard, une note plus poignante encore. La plupart des professeurs du Muséum avaient pu pourtant y assister, conduits par le lrofesseur Unbais, Directeur, qui retraça la belle cărrière du défunt.

Jacques Peldegrix était né à Paris le 12 Juin 1873. Son père, qui avait élé consul, comptait dans sa parenté plusieurs artistes connus comme Nattien et Beruioz. C'est cependant vers les sciences naturelles, si séduisantes pour un esprit observateur et curieux, que se sentit attiré dès l'enlince le jeune Pritritin. Au lycée, il lisait déjà avee ardeur les ouvrages d'Edmond Pentief; intéressé par les théories transformistes, alors fort en vogue, il prépara, dès q̧u'il put, sa licence ès sciences naturelles à la Sorbonne, où il eut des maîtres tels que Bonnier, Delage et Giard. En même temps, il prenait ses grades à la Faculté de Médecine. Pellegrin dut cependant à une circonstance fortuite d'orienter sa carrière vers l'étude des Poissons. Il se plaisait à raconter que c'est à la suite de leçons de piano qu'il fut mis en relation avec VAILLANT, alors titulaire de la chaire d'Ichtyologie du Muséum. Préparateur dès 1897, il ne devait plus quitter ce laboratoire qu'il affectionnait tout particulièrement jusqu'à sa mise à la retraite en 1943. Il en gravit tous les échelons. Docteur en médecine en 1899 , Docteur ès sciences en 1904, il avait été nommé Sous-Directeur en 1908 et, en 1937 enfin, Professeur à la place laissée vacante par Roule. Les honneurs qui s'étaient fait un peu attendre lui furent alors prodigués : il fut nommé successivement membre de' l'Académie des Sciences de Roumanie (1942), de l'Académie des Sciences coloniales (1942) et de l'Académic d'Agricullure (194?). Malheurensement, les tristes événements de 1940, les privations de la guerre et la venue de l'age de la retraite avaient altéré sa santé; il se releva mal d'une mauvaise grippe survenue au début de 1943 . Dès lors, il sentait, comme ceux qui lui rendaient visite, sa fin proche; celle-ci sur. 
vint cependant brusquement, à la suite d'une atteinte cardiaque, dans cette maison de Buffon qui lui était si chère.

Pellegriy a été un grand travailleur. Sauf pendant l'autre guerre (19141918) où il fut mobilisé comme médecin-major et d'où il revint chevalier de la Légion d'honneur, il passa sa vie entière à Paris; son activité scientifique s'y poursuivit sans arrêt pendant quarante-cinq ans et se manifesta par un nombre considérable de publications, la plupart relatives aux Poissons. Mais, en mène temps, qu'il cultivait la science pure où la systématique

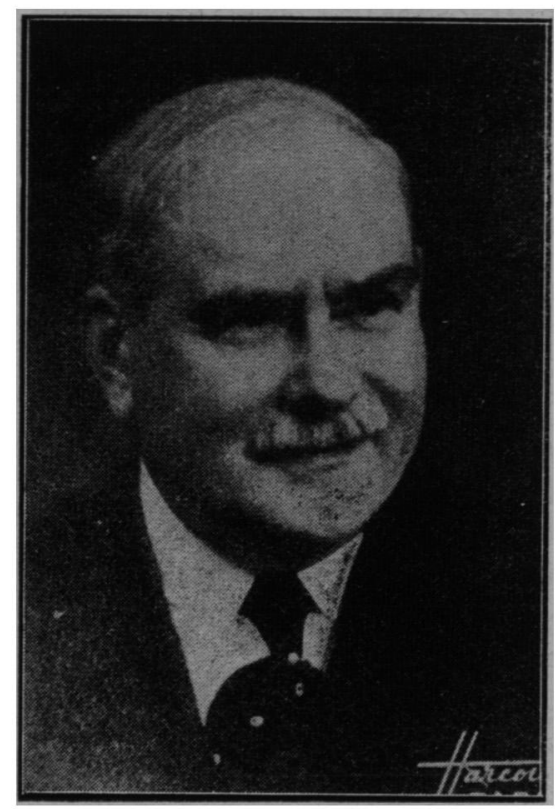

Lo Professeur Jacques Pellegain

(1873-1944)

Cliché Harcourt.

avait la première place, Pel.Legrin ne négligeait pas l'application et, en particulier, l'Aquiculture. Secrétaire général, puis Président de la Société centrale d'Aquicullure et de Pêche, il en dirigeait depuis 1905 le "Bulletin " où ont paru des travaux remarquables, tels celui de J. Sснмгт sur la reproduction de l'Anguille (1922). Conseiller technique des établissements piscicoles de la Ville de Paris, il s'intéressait également à la Station de Salmoniculture de Grattereau. Il contribua, au sein de la Société d'Acclimatation dont il présidait une Section, à développer l'élevage du Poisson et, en particulier, deg Poissons d'ornement.

Mais Pellegrin fut ausi un grand voyageur. Soit seul, soit, le plus souvent, en compagnie du savant et regretté Conservateur des Ealux et 
Forêts Kreitmaxs, Vice-Président de l'Association internationale de Limnologie théorique et appliquée, il participa à de nombreux congrès ou voyages d'études à l'étranger, tant en Europe qu'en Ifrique du Nord.

Ancien Président de la Société Zoologique de France, spécialiste avant tout, comme il en convenait lui-mème, les nombreuses espèces de Poissons exotiques qu'il avait décrites, lui avaient fait une réputation méritée. Sa longue présidence de la Société Centrale d'Aquiculture lui avait valu une place importante dans la Pisciculture française. Ceux qui l'ont approché garderont de Pei.tegris le souvenir d'un causeur agréable et d'un compagnon charmant. Ce fut avant tout un homme de cœur et un ami sûr ; nous le connaissions depuis près de vingt ans et avions pu apprécier son tact, sa courtoisie, sa loyauté. Le Bulletin français de pisciculture, auquel il avait collaboré, offre à $\mathbf{M}^{\text {me }} \mathrm{J}$. Ped.legrin et à M. François Pelie: GRIN, son frère, Sous-Directeur honoraire au Muséum, l'expression de douloureuses condoléances. 